\title{
EL CRECIMIENTO ECONÓMICO DE LA CORONA DE CASTILLA EN EL SIGLO XV: EJEMPLOS ANDALUCES
}

\author{
Miguel Ángel Ladero Quesada
}

Las investigaciones sobre historia económica de la baja Edad Media castellana han tenido un desarrollo reciente y todavía escaso. Puede decirse que hace quince años apenas existían, y nos movíamos entre las intuiciones agudísimas de autores como Carmelo Viñas y Mey, los reflejos que nos llegaban de algunos pioneros en otros países (Ch. Verlinden. J. Heers), las consecuencias que cabía extraer de los estudios, algo más desarrollados, sobre las estructuras económicas de los siglos XVI y XVII, o el análisis serial de algunos aspectos tales como el gran comercio con Indias o la evolución de los precios; no podría olvidar, en este campo, nombres tan prestigiosos y conocidos como los de Klein, Hamilton, Haring, Carande, Vilar, Chaunu, Domínguez Ortiz y F. Ruiz Martín.

Parecía evidente que las raíces, tanto del auge como de la decadencia económica de la Corona de Castilla en la llamada Edad de Oro, habían de buscarse en los últimos siglos medievales, y no sólo en lo que se refería a la vigencia de unas mismas estructuras, sino también en la continuidad de tendencias dentro de la realidad y de la actividad económicas.

La situación de nuestros conocimientos ha mejorado notablemente en los últimos tiempos. Gracias a investigaciones directas sobre fuentes documentales -más escasas que en la Corona de Aragón, por ejemplo, o que en otros países europeos, pero muy interesantes-, sabemos hoy que la evolución de la economía castellana presenta algunos rasgos peculiares dentro de lo que es común a la tardía Edad Media europea. Así procuré manifestarlo hace seis años en un trabajo de síntesis que me sirve como punto de partida para mostrar algunas novedades posteriores de la investigación'.

IM.A. Ladero QUesada, «Población, cconomía y sociedad», en Historia General de España y América, Madrid 1982, V (1351-1516), 3-103. Las notas sólo pretenden facilitar algunas referencias para apoyo de los temas tocados en la conferencia. 
Es probable que, después de algunos intentos de recuperación en los años 1353 a 1362 y 1368 a 1380 , se haya llegado al fondo de la depresión económica y demográfica del siglo XIV, en torno a 1390; pero ya entonces se habían consolidado los fundamentos y estructuras que permitirían el crecimiento y progreso del siglo $\mathrm{xV}$, cuya trascendencia histórica resuita indiscutible, así como lo son también el auge demográfico o las peculiaridades de la organización institucional castellana. Es evidente que en aquel proceso de crecimiento hubo un respeto primordial a los intereses de los dueños de tierra y ganado, de la aristocracia y de los grandes mercaderes, castellanos y extranjeros, que supieron encauzar el auge de la actividad económica en su beneficio.

No se produjo todavía ningún fenómeno importante de arcaísmo económico en el siglo XV pero sí se pusieron los cimientos que harían sencilla su aparición en el futuro, y así se demuestra, tanto si consideramos las formas que adquieren la propiedad de la tierra y las relaciones sociales en torno a ella, como si contemplamos el auge de la ganadería trashumante, las peculiaridades de un comercio exterior basado en la exportación de materias primas y productos agrarios, los límites con que tropieza la actividad manufacturera - sin embargo en auge - o la confianza que ya se otorgaba a unas disponibilidades de metales preciosos, sobre todo el oro, que eran relativamente superiores a las de otros países europeos.

Sin embargo, Castilla vivió en el siglo XV una época de gran expansión, que le permitió actuar como adelantada y pionera de Europa entera en la primera hora de la llamada «civilización atlántica». Después de una primera fase de recuperación, que alcanza aproximadamente hasta 1420, parece observarse otra de gran crecimiento económico hasta 1460. La salida a la crisis de 1462 fue mucho más favorable en Castilla que en otros países hispánicos, a pesar de las guerras civiles y desórdenes del reinado de Enrique IV en su último decenio, de modo que los Reyes Católicos pudieron permitirse en los años 80 una política enérgica que en algunos aspectos dañaba importantes intereses económicos: Inquisición, guerra de Granada, expulsión de los judíos. En el último decenio del siglo XV se reanudó el movimiento expansivo de la economía hasta la crisis, a la vez agraria y demográfica, de los años 1503 a 1507. La coyuntura inmediatamente posterior se conoce muy mal, pero parece que no tardó en recuperarse el ritmo de crecimiento y una situación equivalente a la anterior, posiblemente en torno a 1515 .

Es muy difícil, desde luego, medir con precisión las características y duración de las fases que acabo de indicar, por lo que el margen de hipótesis es grande. En los últimos tres años se han publicado algunos estudios sobre precios y salarios basados en documentos de Burgos, Toledo y Sevilla que 
permiten la formación de series coherentes de datos en muchos casos ${ }^{2}$. Naturalmente, hay que fijarse en los precios reales, expresados en moneda ufuerte" de plata u oro, y no en los nominales, expresados en moneda de vellón o en maravedíes, cuyo incremento es continuo, en especial desde 1430. Parece que, en general, tras un período de estabilidad hasta los años veinte del siglo, la mayor parte de los precios de productos agrarios y materias primas tendieron a descender hasta fin de siglo, salvo en el decenio de los años sesenta, y esto, en un país de población en aumento, significa que la producción se incrementaba aún más deprisa y que se abarataban los costos por unidad, o, en otro caso, los costos de comercialización, gracias a la mejor organización del mercado interior castellano. Por otra parte, los salarios estudiados - casi todos del sector de la construcción - muestran estabilidad o ligero descenso de su capacidad adquisitiva entre 1420 y 1480 . No sabemos cuál sería la evolución de otros tipos de renta.

En fin, los estudios sobre otra variable del sistema económico, la moneda, muestran un aumento de la masa en circulación y de su capacidad como medio de intercambio o transacción, a pesar de las devaluaciones tan fuertes que sufrió la moneda de vellón. Hay, por otra parte, menor estrechez o escasez de oro y plata que en otros países europeos, aunque las crisis de aprovisionamiento señaladas por J. Day entre $1395-1415$ y $1440-1460$ se perciben también en Castilla (ésta última menos) ${ }^{3}$. La observación de los fenómenos monetarios permite comprobar, en resumen, un fuerte y sostenido crecimiento de las actividades mercantiles y una mayor facilidad para las operaciones de capitalización y crédito.

Pero la Corona de Castilla era un ámbito territoríal grande - en torno a $355.000 \mathrm{~km}^{2}$ - y algo heterogéneo, poblado por una cifra de habitantes que acaso se duplicó a lo largo del siglo XV, hasta alcanzar o superar los cuatro millones de seres. Es necesario distinguir matices regionales dentro de las estructuras económicas castellanas, y diversos ritmos de evolución y crecimiento. Utilizando como medio las cifras de los impuestos más importantes de la Corona, en especial la alcabala, indiqué algunos criterios de regionalización económica hace casi diez años, criterios que después han sido útiles también para investigaciones de otros autores. No voy a repetirlos ahora, pero reflexionando sobre ellos, me parece que será más sensato proponer sólo ejemplos y casos relativos a una región de las que componían

${ }^{2}$ A. Mackay, Money, prices and politics in fifteenth century Castile, Londres 1981. R, IzQUIERDo BENTTO, Precios y salarios en Toledo durante el siglo XV, 1400-1475, Toledo 1983.

3J. DAy, *The Great Bullion Famine of the Fifteenth Century», Past and Present, 79 (1978), p. 3-54.

4M. A. LADERo Quesada, La Hacienda Real de Castilla en el siglo Xv, La Laguna de Tenerife 1973; «Para una imagen de Castilla. 1429-1504s, en El siglo xven Castilla. Fuenies de renta y política fiscal, Barcelona 1982. 
la Corona de Castilla entonces, aunque mucho de lo que diga sobre ella es válido también para las otras. Por razones de mejor conocimiento personal, y porque hay más investigaciones recientes, me voy a referir sobre todo a la Andalucía atlántica u occidental, a lo que entonces eran los reinos de Sevilla y Córdoba, y, en ocasiones, también me extenderé al reino de Jaén, esto es, a un ámbito territorial de $60.000 \mathrm{~km}^{2}$.

La Andalucía castellana ofrecía en el siglo xv la imagen de un país en el que la nueva fase A de crecimiento económico había comenzado, de manera precoz, varios decenios antes què en otras partes de Europa e incluso de la Península Ibérica. Una sociedad plena de vitalidad, que se situó en menos de cien años casi a la par, en cuanto a población y capacidad tributaria se refiere, con otras dos grandes áreas de la Corona: el valle del Duero y el antiguo reino de Toledo. Una región que consiguió, con la ayuda del resto de la Corona de Castilla, sostener el esfuerzo casi titánico de la conquista del emirato de Granada entre 1482 y 1492 y prolongarlo, mediante una tarea repobladora, entre 1486 y 1505, que no tiene parangón en ninguna otra parte de Europa. Andalucía se convirtió, además, en el siglo XV en un área de comercio interior en auge, y Sevilla en centro principal del gran comercio europeo, lo que explica por qué aquella ciudad pudo coordinar la gran tarea de la expansión atlántica y convertirse en capital del segundo imperio ultramarino europeo, mientras que Cádiz y Málaga se afirmaban como cabeceras del comercio con el N. de África.

Veremos ahora algunos indicadores y aspectos del crecimiento económico de la Andalucía occidental en el siglo XV, lo que me permitirá trabajar sobre investigaciones recientes y suscitar diversos temas que necesitarían, sin duda, un tratamiento más amplio del que es posible en una conferencia.

\section{EL INCREMENTO DE LA POBLACIÓN}

El crecimiento de población puede considerarse como causa añadida y, al mismo tiempo, como consecuencia en muchos procesos de crecimiento económico, al incrementar los términos de oferta y demanda, esto es, la capacidad de fuerza de trabajo y el volumen de consumo de bienes económicos.

Posiblemente, la Andalucía del Guadalquivir y de las sierras norteñas tocó el fondo de la depresión demográfica del siglo xIV entre 1383 y 1393. Se estima que, en ese momento, no tendría más de 350.000 pobladores. Un siglo y medio después, hacia 1530, la cifra había aumentado a 750.000 u 800.000. El incremento no había sido homogéneo, ni en el tiempo ni en las diversas áreas. Por ejemplo, el hambre de los años 1503-1506 y la devasta- 
dora epidemia de 1507 habían arrebatado tal cantidad de población que, a buen seguro, las cifras estimadas para 1530 no podían ser muy superiores a las de treinta años antes, en torno a 1500. Respecto al reparto por zonas, el reino de Sevilla contaba con 76.000 vecinos pecheros (unos 420.000 h.), y los de Córdoba y Jaén con algo más de 33.000 vecinos cada uno (en tomo a 350.000 h. $)^{5}$.

No disponemos de muchos datos cuantitativos para medir la evolución de la cifra de población en el siglo y medio que he señalado como ámbito de estudio, pero sí que hay un número suficiente de indicadores, todos coincidentes.

- Los padrones de vecindario de la ciudad de Sevilla, entre 1384 y 1533 , indican 2.613 vecinos en la primera fecha, en torno a 5.000 hacia $1435,7.000$ hacia 1485 y 9.000 en 1530 . Esto es, el paso de unas 15.000 a 50.000 personas, sin contar la población flotante y eclesiástica. Sevilla era la mayor ciudad de la Corona de Castilla, pero en su crecimiento hay que considerar un factor peculiar, como es la capacidad de atracción de la ciudad, especialmente desde finales del siglo $\mathrm{Xv}^{6}$.

- $\mathrm{Y}$, sin embargo, los padrones de vecindario de los pueblos de la tierra de Sevilla, más de 50 , dispersos sobre unos $12.000 \mathrm{~km}^{2}$, muestran como, entre 1433 y 1495 , el crecimiento de población fue más rápido en medios rurales. Se ha estimado una tasa media anual de crecimiento del 8 por mil, que llega al 20 por mil en algunas poblaciones de las sierras del $\mathrm{N}$. La tasa media disminuye al 5,4 por mil entre 1495 y 1530 debido al éxodo rural, a fenómenos probables de superpoblación local y a la misma epidemia de 1507 .

El ritmo de crecimiento parece haber sido algo más lento en las zonas de la Campiña y condado de Niebla. El Aljarafe, por ejemplo, pasa de 3.000 vecinos en 1430 a 5.000 en $1495^{8}$. Desde finales del siglo XV, la

${ }^{5}$ F. RUIz MARTiN, aLa población espanola al comienzo de los tiempos modernos», Cuadernos de Historia (Madrid), 1 (1967), p. 189-202; A. Dominguz ORTIZ, wLa población del reino de Sevilla en 1534». Cuadernos de Historia, 7 (1977), p. 337-355: E. CABRFRA MuNoz, «Tierras realengas y tierras de señorio en Córdoba a fines de la Edad Media. Dístribución geográfica y niveles de poblacións, Actas I Congreso Historia Andalucta, Córdoba 1978. Andalucía Medieval, I, p. 295-308.

6 A. COLlANTES DE TERAN, Sevilla en la baja edad media. La ciudad y sus hombres, Sevilla 1977. M. A. LADERo QuesADA. Historia de Sevilla. II. La ciudad medieval, Sevilla 1980 (2a. edición).

7P. Ponsor, "Un cas de croissance démographique précoce: la Basse Andalousie au XVe et au début du xve siècles, Annales de Démographie Historique, 1980, p. 143-153.

$8 \mathrm{M}$. BORRERo FERń́NDEZ, El mundo rural sevillano en el siglo XV: Aljarafe y Ribera, Sevilla 1983. 
cifra de habitantes en algunas grandes aglomeraciones como Carmona o Alcalá de Guadaira tiende a estancarse mientras que, por el contrario, toma auge el crecimiento de pueblos y aldeas menores de la Campiña ${ }^{9}$.

- Hay muchas menos cifras obtenidas de padrones, fuera del reino de Sevilla; las que tenemos hablan en el mismo sentido. Baeza tenía 1.774 vecinos en el año 1407 y 2.709 en 1533 . Úbeda, unos 1.500 vecinos en 1447 y 2.605 en $1533 \ldots$.

- Otro indicador interesante son las iniciativas de repoblación y colonización interior, aunque también responden a motivos políticos, como son el deseo de aumentar los pobladores y, por lo tanto, las fuentes de renta, sobre todo en los grandes señoríos nobiliarios. A esto pueden responder la mayor parte de las pequeñas poblaciones nuevas en el Aljarafe, una decena, que nacen y se consolidan en el siglo XIV ${ }^{11}$. Pero sin crecimiento demográfico no se explicaría el éxito de las 22 nuevas poblaciones surgidas en el reino de Sevilla entre 1400 y 1530 , o de algunas otras en la Campiña de Córdoba ${ }^{12}$.

- Sin embargo, es mucho más espectacular la rápida repoblación en la franja de la antigua frontera de Granada y la primera oleada colonizadora en este reino a raíz de su conquista. Las cifras de los libros de repartimiento y otros documentos señalan un mínimo de 35.000 vecinos repobladores. En efecto, en 1530, de los 204.000 habitantes «pecheros» censados en el reino, más de la mitad son descendientes de repobladores ${ }^{13}$.

- También es significativo del crecimiento urbano la aparición de arrabales y su enorme crecimiento desde el segundo tercio del siglo $\mathrm{XV}$, a veces a costa de las parroquias y barrios de la ciudad amurallada. En Carmona, por ejemplo, el arrabal de San Pedro tenía el 17 por 100 de la población urbana en 1466 y el 34 por 100 en 1528. En Úbeda, los arrabales de San Millán, San Nicolás y San Isidro,

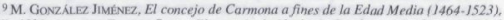
Sevilla 1973. Alfonso Franco Silva, El concejo de Alcala de Guadaira a finales de la Edad Media (1426-1533), Sevilla 1974

$10 \mathrm{~J}$. Rodriguez Mouna, El reino de Jaén en la baja Edad Media. Aspectos demográfi$\cos$ y económicos, Granada 1978. Y datos de la tesis doctoral inédita de M. J. PAREJo DeLgado sobre Bacza y Úbeda en el siglo XV.

"11 M. Gonzzílez JimánEz, La repoblación de la zona de Sevilla durante el siglo xiV. Estudio y documentación, Sevilla 1975.

12 A. Colt.antes de Terin, $*$ Nuevas poblaciones del siglo xv en el reino de Sevillaw, Cuadernos de Hisioria, 7 (1977), p. 283-336.

${ }^{13}$ M. A. LADERo QUESADA, Granada. Historia de un país istamico (I232-1571), Madrid 1980 (2a. edición). 
nacidos en el último tercio del siglo XV, tenían dos mil vecinos en 1591, frente a 1.800 de la ciudad amurallada. Jerez contó con dos arrabales, los de San Miguel y Santiago, desde mediados del siglo $\mathrm{XV}$.

- Y, por último, hay más indicadores, como son la expansión de las tierras cultivadas, la roturación de baldíos de propiedad concejil, los choques entre dedicación agrícola y dedicación ganadera ya a finales del siglo Xv, el incremento de los niveles de renta de la aristocracia..., pero todo ello nos encamina ya a estudiar otras variables demostrativas del crecimiento económico andaluz en el siglo XV.

\section{LAS ACTIVIDADES AGRARIAS}

Los últimos estudios sobre la producción agrícola manifiestan, por una parte, la estabilidad completa que existía entonces en el nivel técnico y en los rendimientos medios que se podían obtener; pero, por otra, una clara modificación y expansión de los terrazgos, en función tanto del aumento del consumo como del estímulo favorable de la actividad comercial interior y exterior ${ }^{14}$.

Los análisis sobre el diezmo eclesiástico de trigo y cebada, cultivados en la proporción teórica de dos a uno o, como entonces se decía, «pan terciado», nos permiten afirmar que la producción andaluza osciló entre 1,5 y 1,65 millones de quintales métricos en los dos últimos decenios del siglo XV, de los que sólo algo más de la mitad correspondían al reino de Sevilla, a pesar de su superior extensión y población.

Las zonas cerealistas más importantes estaban situadas entonces, como hoy, en la Campiña de Córdoba y en su prolongación sevillana, así como en la zona de Jerez; en las áreas sevillanas que acabo de citar se recogía el 70 por 100 de la cosecha de todo el reino de Sevilla. Pero había, también, una tendencia al aumento de la cosecha en áreas menos aptas para el cultivo

${ }^{14}$ M. A. LAdero Quesada y M. Gonz át ez. Jimf́nez, Diezmo eclesiástico y producción de cereales en el reino de Sevilla (1408-1503). Sevilla 1979. M. A. LADERo Quesada, aLos cereales en la Andalucia del siglo XVs, Revista de la Universidad de Madrid, 69 (1969), p. 223-240, y «Producción y renta cerealeras en el reino de Córdoba a finales del siglo XV». Actas I Congreso Hisioria Andalucia, Córdoba 1978, Andalucía Medieval, 1. p. 375-396. M. GonzAlfzZ Jiménez, aLas crisis cerealistas en Carmona a fines de la Edad Medias, Historia. Instituciones. Documentos, 3 (1976), p. 283-307. A. Gonzátez Gómez, «Producción y precio de cereales en Trigueros (Huelva), 1450-1512», En la España Medieval, I, Madrid 1980, p. 129-142. J. PEREZ-EMBID WAMBA, aHacienda eclesiástica e historia económica: las visitas a la iglesia de Lebrija (1476-1521)\%, Hispania, XLII (1982), p. 15-45. B. YUN CASALIILA, Crisis de subsistencia y conflictividad social en Córdoba a principios del siglo xvi Córdoba 1980. 
pero sujetas a fuerte presión demográfica; así sucede en la Tierra Llana de Huelva. cuyo déficit de trigo se compensaba con importaciones por vía terrestre desde el S. de la actual Extremadura, en el condado de Niebla y en Sierra Morena. Así debía de suceder, también, en amplias zonas del reino de Jaén. Sólo en áreas costeras, que se abastecían en parte por medio del comercio marítimo y que estaban dedicadas a cultivos más rentables en el mercado - los vínos en especial - era muy baja la produccíón de cereal.

Hubo un notable aumento de la producción global en la segunda mitad del siglo XV: los datos de los tres primeros decenios indican un promedio de producción, en el arzobispado sevillano, de en torno a 700 mil fanegas, aunque no son demasiado fiables. Los del segundo tercio en tomo a 1,2-1,5 millones. Los del tercio final oscilan entre 1,6 y 2 millones. La misma tendencia alcista en el último tercio del siglo XV se observa en las tierras del reino de Toledo. Además, como en otras partes de Europa occidental de la época, los precios del cereal descendieron a lo largo del siglo, pero en el ámbito andaluz, sobre todo en sus veinte años finales, fue de forma muy brusca. No hubo, por consiguiente, ningún tipo de depresión agrícola ni «decadencia de la agriculturan, contra lo que se lee en algunas obras de síntesis, sino aumento y abaratamiento de la producción, lo que a veces la hizo menos rentable, pero permitió mantener el nivel de consumo de las poblaciones andaluzas, aunque no, seguramente, mejorarlo, porque la presión para aumentar la producción de cereal no provenía sólo del incremento del consumo interior, sino también de los intereses que muchos cosecheros tenian en la exportación: desde el año 1320 los de la Baja Andalucia podían exportar libremente un tercio de las cosechas, una vez garantizado el consumo interno. Y, sin duda, esta posibilidad era un estímulo, pero también producía posibles peligros de desabastecimiento. De todas maneras, no hubo carestías graves en el último cuarto del siglo XV, entre 1474 y 1503, y en aquellos años, por otra parte, comenzó a desarrollarse el sistema de pósitos o cuotas obligatorias de almacenamiento controladas por los municipios, para prever escaseces.

De todas maneras, consideraremos brevemente el posible significado que tuvieron las crisis frumentarias a lo largo del siglo. Los períodos de escasez se explican casi todos en el marco de las fluctuaciones interdecenales propias de las economias de antiguo régimen; las grandes crisis catastróficas no tanto, aunque también algunas sean estructurales. Pero en otros casos, por ejemplo en 1467, 1473 y 1503, hay razones de politica económica: se trata de situaciones de guerra interna, en los dos primeros casos, y hubo una mala política de comercialización en el tercero, acompañada de especulaciones y acaparamientos, con objeto de exportar más y en mejores condiciones, pero provocando, al mismo tiempo, un desabastecimiento peligroso del mercado interior y, por lo tanto, la carestúa, a la que se intentó 
combatir con una tasa de precios que, a su vez, desanimó a los productores; de aquel círculo vicioso no se salió hasta 1508.

También es muy útil repasar lo que se sabe, desde hace muy poco, sobre los otros dos elementos de la clásica «triada mediterráneas, esto es: la vid y el olivo.

Los únicos datos que nos permiten afirmar un crecimiento de la producción vitícola en el siglo XV provienen de las noticias sobre el comercio exterior y sobre el abasto de grandes núcleos urbanos, 0 , a finales de siglo, de las cifras de arrendamiento de alcabalas sobre su consumo, y de las cuentas del diezmo eclesiástico ${ }^{15}$.

No obstante su carácter indirecto, son indicadores bastante seguros. El viñedo, cuya expansión comenzó a raíz de la conquista y repoblación cristianas, fue, a la vez, un «cultivo repoblador», que fijaba el campesinado a la tierra, y una excelente fuente de ingresos para los cosecheros e intermediarios que controlaban los mercados urbanos y las exportaciones o «cargazones» por vía marítima. Precisamente, la mención a estas cargazones se va haciendo más abundante y precisa a medida que el siglo transcurre, así como las medidas de los grandes aristócratas andaluces para fomentar la plantación de viñedos. Hay buenos ejemplos en: Lepe y Ayamonte, Gibraleón, Huelva, Niebla, Rota, Chipiona y El Puerto de Santa María; además de ser muchas de estas localidades señoriales los puntos principales de concentración y embarque de vinos. rumbo al Cantábrico castellano, a Flandes y, sobre todo, a Inglaterra, un cliente antiguo - ya lo era en el siglo xIV - pero que ganó mucha importancia después de las treguas anglo-castellanas de 1467.

De todas maneras, el mercado interior absorbería la mayor parte de la producción, estimada entre los 200.000 y los $280.000 \mathrm{hl} /$ año en el arzobispado de Sevilla. Así lo demuestra el mismo reparto geográfico de las áreas vitícolas, porque junto a algunas predominantemente exportadoras, como son las de Jerez y el condado de Niebla, que producían un 50 por $100-y$ que, en parte, lo consumían-, hay otras en las que el comercio exterior apenas jugaría un papel importante: en la Campiña, en torno a Sevilla, había un «cinturón vitícola» que producía el $25 \%$ del total del arzobispado, y otro tanto procedía de las sierras del N., de las que hoy ha desaparecido prácticamente la vid; sus poblaciones sostenían un intenso tráfico arriero tanto con la Baja Extremadura como con las tierras del valle del Guadalquivir.

La única gran zona olivarera en la Andalucía bajomedieval fue el Aljarafe sevillano $^{16}$. Los olivares eran extremadamente rentables; su propiedad estaba en manos de la aristocracia de Sevilla y de instituciones eclesiásticas, y era frecuente la gestión directa por el propietario, mientras que en otros cultivos predominaban las cesiones de usufructo en arrendamiento o censo. También era normal que miembros del patriciado urbano hispalense intervinieran en el

15 M. A. LADERo QuesADA, «Dos cosechas del viñedo sevillano. 1491 y 1494\%, Archivo Hispalense, 193-194 (1981), p. 41-57.

$16 \mathrm{M}$. BORRERO, op. cit. núm. 8. 
almacenado y comercialización del aceite, tanto para el mercado interior como para la exportación - controlada a menudo por mercaderes genoveses- hacia los centros textiles de Flandes e Inglaterra, hacia Génova misma o hacia la isla de Quios, donde los genoveses poseían grandes fábricas de jabón. También las había, y muy famosas, en la misma Sevilla ${ }^{17}$. Incluso la Corona participaba en ellas, puesto que desde tiempos de Alfonso X se había reservado el diezmo del aceite, sustrayéndolo al ámbito de la fiscalidad eclesiástica.

Contamos con dos series de datos de producción ${ }^{1 \mathrm{~B}}$. En la primera, de los años 1429 a 1448 , el promedio es de 20.000 quintales en los años «llenos» o de buena cosecha - no hay que olvidar que el cultivo era "vecero", es decir, alternaba una cosecha con un año casi estéril. En la segunda, desde 1476 a 1500 , la cifra se ha elevado por término medio a 55.000 quintales. La consecuencia es, pues, clara: de nuevo un fenómeno de crecimiento estimulado por el auge del consumo, de la actividad mercantil, y por la inversión de capitales en aquel tipo de cultivo.

Apenas es posible extender a otros campos estos breves comentarios sobre las estructuras del sector primario y el crecimiento de su producto en el siglo XV. L.as investigaciones sobre Ja ganadería, por ejemplo, son escasas, y carecemos de datos cuantitativos, pero hay varios indicadores sobre su gran importancia económica y su posible crecimiento en el siglo $\mathrm{XV}$ :

- La compilación de ordenanzas locales es un hecho característico de Andalucía, como del resto de Castilla, desde mediados del siglo XV, debido al interés de municipios y aristócratas. En muchas de ellas se regula con gran detalle y extensión todo lo relativo a los regímenes de uso de los pastos, adehesamientos, régimen laboral de los pastores, reuniones o mestas de dueños y cuidadores de ganado, etc. Conocemos hoy, con más o menos detalle, una treintena de mestas locales de este tipo, y bastantes acuerdos interconcejiles de utilización de pastos, concertados o renovados a fines de la Edad Media ${ }^{19}$.

17 J. Gonzál.z. Moreno, Las Reales Almonas de Sevilla (1397-1855), Sevilla 1975.

$18 \mathrm{M}$. A. LADERO QUESADA, «Almojarifazgo sevillano y comercio exterior de Andalucian, Ameario de Historia Económica y Social, 2 (1969) p. 69-116.

${ }^{19} \mathrm{C} . \mathrm{J}$. Bishko, *The Andalusian Municipal Mestas in the 14th-16th Centuries: Administrative and Social Aspects», Actas I Congreso Historia Andalucía, Córdoba 1978. Andalucía Medieval, I, p. 347-374, y «Sesenta años después: La Mesta de Julius Klein a la luz de la investigación subsiguientes, Historia. Instituciones. Documentos, 8 (1981) p. 9-57. M. A. LADERO QUESADA e I. GaĹ́n PARRA, "Ordenanzas locales y sector agrario. El ejemplo del ducado de Medina Sidonia y condado de Nieblax, Congreso de Hisioria Rural. Siglos XV a XIX. Madrid 1984, p. 75-94, y wLas Ordenanzas Locales en la Corona de Castilla como fuente histórica y tema de investigación (siglos xIII al xvm)s, Revista de Esfudios de la Vida Local (Madrid), 217 (1983), p. 85-108. 
- La existencia de zonas eminentemente ganaderas, aparte de los sectores dedicados a pastos en cada municipio de forma habitual o eventual. Por ejemplo, los famosos encinares de Vilches, en Jaén; o los amplios pastizales de la sierra cordobesa; o, también, buena parte de los territorios fronterizos con Granada, conocidos con el nombre de banda morisca, donde la ganadería era aprovechamiento preferente, por razones que se comprenden con facilidad: las noticias sobre escaramuzas y choques de frontera hablan de abundantes robos de ganado, por ambas partes, $y$ los acuerdos de tregua, desde comienzos del siglo XIV, regulaban el comercio de reses.

- La exportación de cueros vacunos era un negocio importante en todo el reino de Sevilla, en especial en la capital y en las áreas del bajo Guadalquivir y del Guadalete. Así lo muestra la cuantía de la llamada «renta de los cueros», los monopolios de compra de cueros que otorgaron a veces los reyes a diversos personajes políticos y las menciones a los «cueros de Sevilla» que se hallan en todos los mercados europeos de la época, desde Génova y Marsella hasta Amberes. Pero, además, no se trataba sólo de cueros sevillanos; la ciudad concentraba parte de la producción cordobesa y del reino de Jaén, para su posterior exportación, así como cueros de Berbería y materiales auxiliares indispensables para la manufactura o curtiduría, como, por ejemplo, el zumaque, procedente también de Jaén en muchas ocasiones.

- La producción de lana en la sierra de Córdoba y, en general, en todas las zonas serranas norteñas era elevada, y se combinaba con el uso de buena lana merina de los rebaños trashumantes que invernaban en La Serena y el Valle de Alcudia, para alimentar una manufactura textil de calidad y en evidente crecimiento a lo largo del siglo XV, tanto en Córdoba como en Baeza. Por otra parte, Córdoba y Sevilla eran centros de contratación de la lana merina extremeña y andaluza, comprada anticipadamente por mercaderes genoveses y, desde el último tercio del siglo XV, por los burgaleses cada vez más numerosos, como demuestran los contratos notariales y exportada, primero por medio de carretas o de barcazas fluviales hasta Sevilla, y, desde allí, por vía marítima ${ }^{20}$.

20 J. EdWards, Christian Cordaba. The City and its Region in the Late Middle Ages. Cambridge 1982, y también oligarchy and Merchant Capitalism in lower Andalusia under the Catholic Kings: The case of Cordoba and Jerez de la Fronteras, Historia. Instituciones. Documentos, 4 (1977), p. 11-33, «El comercio lanero en Córdoba bajo los Reyes Católicos». I Congreso Historia Andalucia. Córdoba 1978, Andalucía Medieval, I, p. 423-428. E. OTTE. «El comercio exterior andaluz en la baja Edad Medias, II Coloquio de Historia Medievai Andaluza. Hacienda y Comercio. Sevilla 1982, p. 193-240 (estudio sobre protocolos notariales sevillanos). 
- Si el negocio de la lana y cueros interesaba a muchos aristócratas de Sevilla y Córdoba, el de la carne para consumo parece que afectó sobre todo - igual que el de la venta de paños al por menor- a sectores acomodados de las clases medias urbanas, por lo que ha dejado menos huellas documentales, todavía en el siglo XV; pero la observación de las alcabalas sobre la venta de carne y de las sisas municipales impuestas sobre el producto permite comprobar claramente un aumento del consumo, en especial en Jerez, Écija, Córdoba o Jaén, correlativo al aumento de población más que, seguramente, a una mayor capacidad individual de consumo ${ }^{21}$.

Por el contrario, en Sevilla, aunque también es importante la alcabala de la carne, se observa cómo la supera en importancia la del pescado, a pesar del precio menor de este producto. Las investigaciones muestran, en efecto, un crecimiento de la importancia de los distintos tipos de pesquería que entonces se practicaban. El pescado del tramo final del Guadalquivir, y el de la costa atlántica andaluza fueron la primera base del consumo interior, pero a medida que avanzaba el siglo XV, a las pesquerías próximas se van añadiendo las efectuadas en bancos cada vez más lejanos: hacia 1450 se faenaba ya de manera habitual en los canarios y saharianos ${ }^{22}$. El negocio era de tal importancia, que algunas ordenanzas municipales de poblaciones costeras - Palos es un buen ejemplo ${ }^{23}$ - se dedicaron casi exclusivamente a reglamentarlo, a asegurar el buen cuidado de los pinares que proporcionaban la materia prima para la construcción de carabelas o el régimen comercial de un producto complementario imprescindible, como era la sal. Así sucedería que el descubrimiento de América fue, entre otras cosas, una aventura de pescadores andaluces, en el momento en que las rentas «del lavar de la sardina», la «cuarentena del pescado» y las alcabalas y almojarifazgos sobre el pescado fresco o salado alcanzaban una gran importancia tanto en la fiscalidad señorial de los puertos onubenses y gaditanos ${ }^{24} \mathrm{como}$ en la de la Corona, en la misma Sevilla.

21 M. A. LADERO QUESADA, «Fiscalidad y sector terciario en la baja Edad Media andaluzaw, II Coloquio de Historia Medieval Andaluza, Sevilla 1982, p. 7-38.

22 A. RUMEU DE ARMAS, «Las pesquerías españolas en la costa de África», Hispania, 130 (1975), p. 295-319.

23 M. A. LADERo QuesADA, ePalos en vísperas del Descubrimientos, Revista de Indias, 153-154 (1978), p. 471-506.

${ }_{24}$ M. A. LADERo Quesada, *Los señores de Gibraleon*, Cuadernos de Historia, 7 (1977), p. 33-95, eLos sehorios medievales en el ámbito de Cádiz y Jerez de la Fronteras, En la España Medieval, II (1982), p. 543-572, y «El sefiorío de Ayamonte hacia $1500 \mathrm{~m}$ (en prensa, Universidad de Niza). 
El tercer tipo de pesquería era mucho más especializado y estacional, pues se trata de la almadraba del atún, efectuada en muchos puntos de la costa atlántica andaluza durante los meses de mayo y junio, completada con trabajos, en las mismas playas, de troceado, salazón y envasado de los atunes. Era un negocio en manos de la alta aristocracia - Guzmán, Ponce de León, La Cerda-, que solía concertar anticipadamente la venta a mercaderes extranjeros, en especial italianos ${ }^{25}$. El mantenimiento y crecimiento de esta actividad económica estaba asegurado, casi sin más límite que el propio agotamiento de los atunes, pero se relacionaba sobre todo con factores de mercado exterior.

Volvamos ahora al espacio territorial andaluz propiamente dicho, para señalar cómo aquellas transformaciones y fenómenos de crecimiento en el sector primario afectaban al régimen de propiedad y uso de la tierra en aspectos muy diversos entre sí.

- A finales del siglo XV comienzan a menudear los enfrentamientos por el uso de las tierras baldías, de disposición comunal, y de las zonas abiertas temporalmente al pasto, en los terrazgos cultivados; por una parte, entre dueños de ganadería estante, que pretenden mantener abierto su uso, y propietarios de tierra, que quieren acotar o adehesar el pasto de sus fincas; por otra parte, entre vecinos de cada lugar y dueños de ganado trashumante, encuadrado en la Mesta general o Mesta de los serranos, que obtuvo sustanciales apoyos jurídicos a sus pretensiones desde 1501 (prerrogativa de posesión). El trabajo de los llamados jueces de términos fue muy grande en toda Castilla a partir de la disposición que lo ordenaba, dada en las Cortes de Toledo de 1480. Se trataba, en resumen, de conciliar los intereses de procesos de crecimiento agrícola y ganadero que hasta entonces, fines del siglo XV, apenas habían chocado en Andalucía ${ }^{26}$.

- A lo largo de todo aquel siglo, el precio de la tierra laborable aumentó, en líneas generales, y la inversión de dinero en su compra fue un negocio seguro y rentable a largo plazo, que practicaron los miembros de la alta aristocracia territorial y de los «patriciados urbanos» de las ciudades, completándolo con la toma en arriendo o censo a largo plazo de tierras de propie-

${ }^{25}$ M. A. Ladero Quesada, „Unas cuentas en Cádiz (1485-1486)», Cuadernos de Estudios Medievales, II-III (1974-1975), p. 85-120.

${ }^{26} \mathrm{M}$. A. LADERo QUESADA, “Donadíos en Sevilla. Algunas notas sobre el régimen de la tierra hacia 1500\%, Archivo Hispalense, 181 (1976), p. 19-91. 
dad eclesiástica ${ }^{27}$. A fines del siglo, al menos un 15 por 100 de las rentas de los duques de Medina Sidonia procedían de sus propiedades rústicas ${ }^{28}$. Entre 1423 y 1515 — es otro ejemplo-. adquirieron los Ponce de León - condes y luego duques de Arcos- el 90 por 100 de las propiedades agrarias de que dispuso el linaje en la Edad Moderna ${ }^{29}$. Estudios recientes muestran cómo el patriciado urbano de Sevilla invertía continuamente en la compra o en el arriendo de tierras con un claro espíritu moderno de «búsqueda de beneficios líquidos de la producción agrícola $[\ldots]$ dentro de un marco económico donde el mercado juega un papel importante» (A. Collantes de Terán), hasta el punto de gestionar directamente la explotación de los tipos de cultivo más rentables, en especial el olivar ${ }^{30}$.

- Se comprende fácilmente que en aquellas circunstancias la gran propiedad haya crecido a costa de la mediana y pequeña, agudizando un proceso de concentración tradicional en la historia agraria andaluza, pero no para empobrecer la actividad agrícola —al menos entonces - sino para estimularla, porque obligaba a invertir capitales y promovía su relación con los factores de mercado.

- De todos modos, la conversión de muchos campesinos en simples asalariados e incluso en jornaleros, comenzó a ser inevitable, y aquello ocurría en medio de una presión demográfica creciente, de modo que los más pudientes de entre ellos presionaron a los municipios hasta conseguir que se regulase el uso privado y la puesta en cultivo de parte de las tierras baldías comunales. Aquello comenzó a ocurrir en el último tercio del siglo XV y continuó durante el XVI. El resultado fue asegurar el crecimiento de algunas producciones,

27 A. COLLANTES DE TERAN, we latifundium sevillan aux xive et xve siècles. Ebauche d'une problematique», Mélanges de la Casa de Velázquez (Madrid), XII (1976), p. 101-125; "Génesis de la gran propiedad en la baja Edad Media: la propiedad eclesiástica sevillanaw, La economía agraria en la hístoria de España. Propiedad, explotación y rentas. Madrid 1978, p. 133-140. M. GonzALEz. JimínEZ, ePropiedades y rentas territoriales del cabildo de la catedral de Sevilla a fines de la Edad Medias, Cuadernos de Historia, 7 (1977), p. 167-212.

${ }^{28}$ E. Solano Rutz, *La hacienda de las casas de Medina Sidonia y Arcos en la Andalucía del siglo XVs, Archivo Hispalense, 168 (1972), p. 85-176.

${ }^{29}$ R. Mata OLmos, aParticipación de la alta nobleza andaluza en el mercado de la tierra. La casa de Arcos (siglos XV.XVII)n, Congreso de Historia Rural. Siglos XVal XIX, Madrid 1984, p. $681-710$.

${ }^{30}$ M. BORRERO, op. cit, nota 8. A. Coll.antes de TERÁn, eUn modelo andaluz de explotación agraria bajomedieval», Actas de las I Jornadas de Metodología Aplicada de las Ciencias Históricas, Santiago 1975, II, Historia Medieval, p. 135-154. M. Borrero FerrnánDEZ, *La propiedad de la tierra en el Aljarafe sevillano durante la Baja Edad Medias, Congreso de Hisioria Rural, Madrid (1984), p. 95-108. 
pero también hacer cada vez más difícil el equilibrio entre las diversas partes del sistema económico agrario, y, posiblemente, acelerar en ocasiones procesos de deforestación y de empobrecimiento de suelos.

De todos modos, era una solución de compromiso inevitable entre la presión demográfica, las tendencias a la privatización de tierras y usos comunales, la fuerza de los ganaderos, el peligro de ruptura del equilibrio agrícola-pastoril, y el peso y las consecuencias sociales del aumento de la gran propiedad. Diversos municipios repartían lotes de tierra comunal entre los vecinos que lo solicilaran, temporal o perpetuamente, a cambio de una renta pequeña, censo o tributo $^{31}$. Más adelante se apelaría a la roza y cultivo de unas u otras zonas de los montes comunales, que se irían alternando o rotando, de modo que siempre hubiera unas en explotación y otras en proceso de repoblación o regeneración forestal. Es interesante señalar que, en muchas ocasiones, eran beneficiarios de aquellas prácticas los vecinos que ya tenían propiedad de tierra, no los simples asalariados o jomaleros.

\section{EL COMERCIO}

Al estudiar el crecimiento económico en el sector primario ha habido ya ocasión de manifestar la importancia que tenía el auge del comercio no sólo como consecuencia sino también como activador de aquellos fenómenos. Pero hay dos ámbitos que conocemos de manera muy desigual: el primero se refiere al comercio y mercados interiores, sobre todo en lo referente al abastecimiento de los núcleos urbanos ${ }^{32}$; el segundo atañe al comercio exterior por vía marítima, que es el aspecto mejor conocido de la realidad económica andaluza en el siglo XV, sobre todo por lo que toca a la capitalidad sevillana de aquellos tráficos mercantiles.

Hay que hacer referencia a algunos aspectos generales: Primero, a la relación, tantas veces comprobada, entre la influencia del mercado y la especialización productiva en determinadas comarcas andaluzas; los ejemplos que ya he mencionado sobre los cereales, el vino, el aceite o la ganadería bastan para demostrarlo; segundo, a la existencia o no de un mercado común para toda la cuenca del Guadalquivir y sus zonas próximas de Extremadura y Castilla la Nueva, en lo relativo a determinados productos. Algunos autores lo niegan y afirman que hay factores locales o comar-

31 M. González Jiménez, op. cit. nota 9. V. también D. E. VASSBERG, Land and Society in Golden Age Castile. 1984.

${ }^{32}$ A. MACKAY, *Comercio/mercado interior y la expansión económica del siglo XV», II Coloquio de Historia Medieval Andaluza. Sevilla 1982, p. 103-123. 
cales predominantes en la formación del mercado, $y$, en todo caso, una «descentralización" predominante. Estoy de acuerdo, pero también me parece que la demanda mercantil y las posibilidades de transporte terrestre - se ha minusvalorado el papel de la arriería y carretería ${ }^{33}$ - facilitaban la unificación mercantil relativa a determinados productos y aspectos o, por lo menos, la existencia de centros de demanda y redistribución dominantes en todo el espacio andaluz, y éste era el caso de Sevilla.

Las técnicas e instrumentos mercantiles de la época hacían que esto fuera posible. Consideremos, por ejemplo, la función creciente de la moneda y de los medios de crédito y capitalización vinculados a ella. Toda la actividad mercantil andaluza estaba penetrada por el hecho de ser Sevilla la principal plaza castellana de comercio de dinero y metales preciosos. La oferta monetaria y la fluidez de circulación material del dinero eran mayores que en otras ciudades del país.

La ceca real o «casa de la monedan de Sevilla era la más importante; hacia 1440 podía labrar 792.000 reales de plata al año, mientras que la de Toledo no superaba los 600.000 y la de Burgos, los 400.000 . También en ella, según leemos en las actas de Cortes de 1451, «se labra mucho más oro que en todos vuestros regnos", declaran los procuradores a Juan II, Y ello se debía a la importación del procedente de África, Un ejemplo: en 18 meses, entre el otoño de 1457 y la primavera de 1459 , la ceca sevillana labró oro por valor de 65.600 doblas y 2.820 florines de oro, más 502.392 reales de plata.

Como apenas es posible cuantificar el estudio de estos fenómenos, el margen de hipótesis es grande. Pero, evidentemente, el oro salía de la Andalucía atlántica y su exportación producía beneficios, acaso más de un 25 por 100 según algunas fuentes italianas. En 1377, por ejemplo, de 68.600 liras de oro entradas en Génova, 54.400 eran de procedencia hispana. Es de suponer que aquellos tráficos beneficiarian también a los intermediarios andaluces y que favorecerían la capacidad de acumulación de capital; en los inventarios de bienes muebles de la aristocracia regional, las sumas acumuladas en oro y plata, amonedado o no, son muy fuertes. Y también lo son las cifras de moneda manejadas en las dotes de hijas de la alta nobleza, y la fluidez de sus inversiones - en tierra, por ejemploutilizando moneda.

¿Era Sevilla, ya en la primera mitad del siglo Xv, «la capital económica y financiera de Castilla ${ }^{34}$ ? Esto no pasa de ser una suposición razonable, en algunos aspectos, pero la gran banca sevillana no tomaría auge hasta el primer decenio del siglo XVI. Sin embargo, no cabe duda de que las

33 P. Ponsor, «En Andalousie occidentale: systèmes de transports et développement économique (xvie-xixe siècles)», Annales ESC, 6 (1976), p. 1.195-1.212.

${ }^{34}$ E. OTTE, *Sevilla, plaza bancaria europea en el siglo XVIv, Dinero y Crédito (siglos XVI al XIX). Madrid (1978), p. 89-112. 
medidas de liberalización en el establecimiento de bancas o tablas de cambios, tomadas por Juan II entre 1435 y 1445 favorecieron una concentración bancaria en Sevilla y Jerez que no tiene igual en el resto de Casti$\mathrm{Ila}^{35}$. Ignoramos el alcance de sus operaciones, pero me parece que serían, más bien, subsidiarías de las finanzas del gran comercio internacional practicado por genoveses y otros italianos, y que estarían destinadas sobre todo a negocios de ámbito local o regional.

Los medios de la actividad mercantil aumentaron y maduraron en la Andalucía del XV. Me refiero a los lugares del comercio, ante todo, porque, aunque el número de ferias no creció mucho y las novedades afectaron, especialmente, a zonas rurales, contribuyendo a movilizar su producción ${ }^{36}$, hubo un ordenamiento minucioso, a cargo de las autoridades locales, del comercio urbano: mercados, tiendas, alhóndigas, alcaicerías, reventa a cargo de regatones, reglamentación de los oficios artesanos, papel de los corredores «de oreja» o intermediarios diplomados en las transacciones. Todo aquello hizo que fueran cada vez más frecuentes las figuras de comerciantes profesionales, en diversos ramos y a diversa escala, desde el pequeño tendero al gran «señor de los paños», que dominaba la manufactura textil ${ }^{37}$. Es cierto que se partía de bases y prácticas de comercio anteriores, pero, y éste es otro indicador, no siempre cra así; el auge de la actividad notarial, del volumen de documentación conservada, es sintomático, aunque consideremos que haya habido pérdidas de los protocolos más antiguos, porque sólo se apela a la fe pública representada por el notario cuando los tratos mercantiles son más importantes y continuos.

En cualquier caso, lo que conocemos mejor, hoy por hoy, es el comercio exterior, en sus grandes líneas. Muchos aspectos de su evolución se perciben siguiendo la variación de los precios de arrendamiento de la aduana real o almojarifazgo mayor de Sevilla y su reino, aunque hay que tener en cuenta los factores no económicos sino políticos que intervienen en la contratación de su arrendamiento, por lo que se ha de apelar a datos complementarios y correctores.

Hay un crecimiento suave de la renta entre 1420 y 1450 (se pasa del índice 100 al 119 en ocasiones), seguido por un fuerte incremento entre 1455 y 1471, que sólo se rompe durante la crisis de los años 1462 a 1464 (se alcanza un índice 150). En los años 1480 a 1493 hay una depresión fuerte, con su máximo en 1483, que ha de atribuirse también a motivos políticos, como las actuaciones inquisitoriales, que hicieron huir a merca-

35 F. Ruz Martís, «La Banca en España hasta 1782 , en El Banco de España. Una historia económica, Madrid 1970; y «Demanda y oferta bancarias $(1450-1600)$, Melanges... Braudel, París 1972, p. $521-536$.

36 M. A. LADERo QuesADA, «Las ferias de Castilla. Siglos XII a XVm. Cuadernos de Historia de España (Buenos Aires), LXVII-LXVIII (1982), p. 269-347.

${ }^{37}$ A. Collantes DE TERAN, op. cit, nota 6. 
deres judeoconversos, y la guerra contra Granada. A continuación se produjo una recuperación rápida, desde 1494 a 1503 , en cuyo transcurso la renta recuperó el nivel que tenía en 1460 . Da la impresión, por lo tanto, de que hubo una evolución no lineal de la actividad mercantil, y de que tal vez el mejor momento del siglo fueron los años 1455 a 1471 , correspondientes al reinado de Enrique IV.

Los diversos aspectos cualitativos del comercio exterior de la Andaluć́a atlántica son bastante conocidos y he contribuido a difundirlos en alguna obra de síntesis reciente, por lo que no los repetiré ahora ${ }^{38}$. Se refieren a: los productos agrarios y materias primas, más jabón, «bizcocho» y cerámica, contra importaciones de paños, manufacturas, sedas y tintes, hierro y madera, azúcar, y productos agrarios del N. de África; el aprovechamiento de una situación excepcional en la ruta Italia-Flandes y en la cabecera de las rutas hacia África; la relación con plazas mercantiles que se escalonan desde Flandes, Inglaterra, Normandía y Bretaña hasta Berbería, el Mediterráneo occidental, $\mathrm{y}$ las ciudades italianas; los tipos de mercaderes, genoveses sobre todo, pero también otros: italianos, burgaleses y también andaluces, aunque sujetos a un control exterior de los grandes capitales mercantiles y de las directrices del comercio; los transportistas por vía marítima: barcos andaluces de pequeño calado en abundancia, naos y buques de la costa cantábrica —en especial vascos-, más importantes, sin contar, por supuesto, con las galeras y naos de mercaderes extranjeros siempre presentes, a pesar de las «actas de navegación» dictadas por los reyes de Castilla en 1398 y, de nuevo, en 1500.

Se ha escrito a menudo sobre el carácter «colonial» de aquellos tráficos. Terminaré recordando algunas reflexiones elementales a este respecto. Los términos de relación entre dueños de la tierra y de sus productos y dueños de los negocios y manufacturas son radicalmente distintos en una economía agraria tradicional y en una economía industrial contemporánea. Se puede afirmar, incluso, que las situaciones de predominio se producen a favor de los primeros, entonces, y no de los segundos, y que, por lo tanto, la posición mercantil de Andalucía - como de casi toda Castilla - en el siglo XV no implicaba ningún tipo de subdesarrollo, marginalidad o sujección colonial. Se trataba, por lo contrario, de una opción, tal vez la más fructífera en aquel

38 Véase M. A. LADERo QUeSADA, op. eit., notas 1, 6 y 18. E. OTTE, op. cit., nota 20: y «Los Botti y los Lugor, III Coloquio de Historia Canario-Americana, Las Palmas de Gran Canaria 1980, 1. p. 47-86. Todas las ponencias y comunicaciones del II Coloquio de Historia Medieval Andaluza. Hacienda y Comercio, Sevilla 1982. J. HeErs, Gènes au xvème siècle, París 1961. F. Pérrz EmBID, aNavegación y comercio en el puerto de Sevilla en la Baja Edad Mediar, Anuario de Estudios Americanos, XXV (1968), p. 43-93. A. RUMEU DE ARMAS, Cadiz metrópoli del comercio con África en los siglos XV y XVt, Cádiz 1976. P. ChaunU. «Séville, pôle de croissance? (XV, XVI, XVII, XVII, siècles) \%, Città, mercanti, dottrine nell 'economia europea dal oV al xvm secolo, Saggi in memoria di Gino Luzzato, Milán 1964. p. 255-276. 
momento - sin duda, la más conservadora desde el punto de vista socialentre las que ofrecían aquellos regímenes de economía agraria y sociedad feudal bien desarrollados ${ }^{39}$. Y, desde luego, era la opción más segura; los grupos sociales dirigentes cuya renta se basaba en la tierra y en sus productos convenientemente comercializados estaban mucho menos sujetos a las consecuencias de crisis coyunturales o bélicas que no aquellos otros cuya potencia se basaba en el control de rutas y capitales mercantiles. Por ejemplo, una guerra civil, entre 1462 y 1472, pudo arruinar el comercio catalán, pero quince años de disturbios, entre 1464 y 1479, apenas modificaron las condiciones del castellano y andaluz.

Es cosa distinta afirmar que la evolución futura alteraría aquel estado de cosas, con el desarrollo del primer capitalismo mercantil atlántico, o con las revoluciones industriales, más adelante. Pero esto no era así en el siglo XV, ni todavía en el XVI, y sería imposible comprender el auge demográfico, la prosperidad económica, el crecimiento urbano o los mismos fenómenos de consolidación de toda una estructura social en Andalucía si se aplicaran anacrónicamente criterios socioeconómicos actuales sin matizarlos y contrastarlos ante una realidad histórica muy diferente como era la de Andalucía hacia 1492, después de varios decenios de crecimiento económico, y como centro cosmopolita de un comercio importantísimo, a la vanguardia de las nuevas tendencias y corrientes mercantiles que nacían en el Atlántico medio.

${ }^{39}$ M. A. LADERo QUESADA, «Aristocratie et régime seigneurial dans l'Andalousie du XVème sièclen, Annales ESC, 6 (1983), p. 1.346-1.368. R. PIKE, Aristócratas y comerciantes. La sociedad sevillana en el sigio XVI. Bareelona 1978. 